\title{
The Risk of Multimorbidity Associated with Overweight and Obesity: Data from the Brazilian National Health Survey 2013
}

\author{
Thaynã Ramos Flores ${ }^{1}$, Ana Paula dos Santos Rodrigues², Rosália Garcia Neves ${ }^{3}$, Sandro Rodrigues Batista ${ }^{4}$, \\ Doralice Severo da Cruz Teixeira ${ }^{5}$, Erika Aparecida da Silveira ${ }^{4}$, Deborah Carvalho Malta ${ }^{6}$, Bruno Pereira Nunes ${ }^{1,7}$ \\ 'Postgraduate Program in Epidemiology, Federal University of Pelotas, Pelotas; ${ }^{2}$ Superintendence of Health Surveillance, Goiás State Health Department, Goiás; \\ ${ }^{3}$ The Third Regional Health Coordination, Pelotas; ${ }^{4}$ Faculty of Medicine, Goiás Federal University, Goiânia; ${ }^{5}$ São Paulo Municipal Health Department, Sao Paulo; \\ ${ }^{6}$ Department of Maternal and Child Nursing and Public Health, School of Nursing, Federal University of Minas Gerais, Belo Horizonte; ${ }^{7}$ Department of Nursing in \\ Collective Health and the Postgraduate Program in Nursing at the Federal University of Pelotas, Pelotas, Brazil
}

Background: An increase in body mass index (BMI) is strongly associated with the occurrence of multimorbidity, and overweight and obesity are contributing factors for the increase in morbidities. Thus, the present study aimed to evaluate the occurrence of multimorbidity and associated factors in Brazilian adults with and without overweight or obesity.

Methods: This was a cross-sectional population-based study with data from the National Health Survey (2013) including individuals aged 18 years or older. Multimorbidity was defined as having $\geq 2$ diseases from the list of 15 morbidities on the self-reported questionnaire (self-reported medical diagnosis in life). BMI was categorized as: $\leq 24.9 \mathrm{~kg} / \mathrm{m}^{2}$ (low weight and eutrophy), $25.0-29.9 \mathrm{~kg} / \mathrm{m}^{2}$ (overweight), and $\geq 30.0 \mathrm{~kg} / \mathrm{m}^{2}$ (obesity). Sex, age, and schooling were the covariates. Poisson regression was used for crude and adjusted analyses for the variables representing access to health services estimating the prevalence ratio (PR) and 95\% confidence inter$\operatorname{val}(\mathrm{Cl})$.

Results: The total sample consisted of 59,402 individuals. The prevalence of multimorbidity was $25 \%$ overall and was higher among overweight (25.8\%) and obese (32.5\%) individuals. Obese women 60 years or older had a higher occurrence of multimorbidity (80\%). In the adjusted analysis, a lower prevalence of multimorbidity was observed among those with higher educational levels in all BMI classifications: low weight/eutrophy, PR=0.66 (95\% Cl, 0.58-0.75); overweight, $\mathrm{PR}=0.62$ ( $95 \% \mathrm{Cl}, 0.56-0.70)$; and obesity, $\mathrm{PR}=0.75$ ( $95 \% \mathrm{Cl}, 0.67-0.85)$.

Conclusion: A higher prevalence of multimorbidity was found among obese women who were 60 years of age or older. Schooling was an associated factor regardless of BMI.

Key words: Multimorbidity, Overweight, Obesity, Body mass index, Prevalence

\author{
Received October 8, 2020 \\ Reviewed February 11, 2021 \\ Accepted February 16, 2021 \\ ${ }^{*}$ Corresponding author \\ Thaynã Ramos Flores \\ https://orcid.org/0000-0003-0098-168 \\ Postgraduate Program in Epidemiology, \\ Federal University of Pelotas, Marechal \\ Deodoro, 1160, 3rd floor, Pelotas \\ 96020-220, Brazil \\ Tel: +55-53-3284-1300 \\ Fax: +55-53-3284-1300 \\ E-mail: floresrthayna@gmail.com
}

\section{INTRODUCTION}

Overweight and obesity have increased alarmingly in recent decades. The overall prevalence of overweight, defined as body mass index (BMI) $\geq 25.0 \mathrm{~kg} / \mathrm{m}^{2}$, increased by $27.5 \%$ between 1980 and 2013, from 857 million to 2.1 billion individuals. ${ }^{1}$ The increase in
$\mathrm{BMI}$ is associated with increased mortality and various health problems, such as cardiovascular disease and stroke, which are mainly mediated by high blood pressure, cholesterol, and blood glucose. ${ }^{2}$ In addition, obesity is associated with a reduction in life expectancy, worsening in quality of life, higher unemployment, lower productivity, and social disadvantage. ${ }^{3}$ 
Overweight and obesity contribute to the occurrence of concomitant diseases in individuals. ${ }^{4}$ The coexistence of one or more morbidities is called multimorbidity and has been increasingly studied because it is associated with higher mortality, reduced functional capacity, polypharmacy, reduction in quality of life, worse self-rated health, and lower continuity of care. ${ }^{5-8}$ In recent years, there has been an increase in the prevalence of multimorbidity in several countries, probably due to the improved longevity of populations related to advances in medicine and preventive aspects in public health. It is worth highlighting that multimorbidity occurs not only in older individuals, but also in younger individuals. ${ }^{9-11}$ In Brazil, the prevalence of multimorbidity in adults was estimated at $22.2 \%$ for two or more morbidities and $10.2 \%$ for three or more morbidities. ${ }^{12}$ Obesity is associated with a higher prevalence of multimorbidity; $;^{11,13-15}$ however, there are few studies evaluating overweight, using the BMI cutoff point of $\geq 25.0 \mathrm{~kg} / \mathrm{m}^{2}$.

The epidemiological transition and, consequently, the higher frequency of chronic noncommunicable diseases in the population plays a determining role in the prevalence of multimorbidity. Health data from 28 countries showed that those with low to moderate incomes experienced a rise in multimorbidity with increasing age and a positive nonlinear association with income. ${ }^{16}$ This same study observed an inverse association between multimorbidity and education, especially in young people when compared to individuals aged 60 years or older. ${ }^{16}$ In Brazilian men and women over the age of 60 , there was a higher occurrence of morbidities (five or more) in individuals with lower incomes compared to those with higher incomes, and the same trend was observed for educational level when considering the occurrence of three or more, four or more, and five or more morbidities. ${ }^{17}$ Additionally, a systematic review and meta-analysis of 24 cross-sectional studies found a $64 \%$ greater chance of multimorbidity (odds ratio [OR], 1.64; 95\% confidence interval [CI], 1.41-1.91) in individuals of low compared to high educational level; however, there was a high degree of heterogeneity in the studies. Deprivation has been consistently associated with increased risk of multimorbidity. ${ }^{18}$ The relationship between multimorbidity and sociodemographic factors and inequalities in individuals with $\mathrm{BMI} \geq 25.0 \mathrm{~kg} / \mathrm{m}^{2}$ is still unknown.

Identifying the prevalence of multimorbidity according to overweight and obesity in the Brazilian population and the associated inequalities is important in developing more effective approaches that address the needs of each group of individuals. An increase in BMI is strongly associated with the occurrence of multimorbidity, and overweight and obesity are contributing factors for the increase in morbidities. ${ }^{14,15}$ Thus, the present study aimed to evaluate the occurrence of multimorbidity and associated factors in Brazilian adults with and without overweight/obesity.

\section{METHODS}

This was a cross-sectional, population-based study with data from the National Health Survey (Pesquisa Nacional de Saúde [PNS]) conducted in 2013 by the Brazilian Institute of Geography and Statistics (IBGE) and the Ministry of Health in Brazil. ${ }^{19,20}$ The sample is representative of residents of permanent households, located in urban or rural areas, in the five major geographical regions, 27 federation units, capitals, and other municipalities. The selection of the PNS sample was carried out in three stages: the first stage selected the census tracts, followed by the second stage which selected the households, and finally the third stage which selected individuals aged 18 years or older. Data collection was performed by trained interviewers using handheld computers called PDAs (personal digital assistants). More details can be found in the methodological study. ${ }^{19,20}$

We included all individuals at least 18 years of age who had information for the 15 morbidities that were evaluated and the anthropometric measurements required for BMI calculation (i.e., weight and height). To evaluate multimorbidity, a list containing the 15 morbidities assessed by the individual's report of receiving a medical diagnosis was used. Morbidities were identified through the question, "Has any doctor already diagnosed you with...," and the following diseases and risk factors were listed: hypertension; hypercholesterolemia; depression; diabetes; arthritis or rheumatism; bronchitis, asthma, or wheezing; work-related musculoskeletal disorders; cancer; heart problems; stroke; chronic renal failure; other lung disease; chronic obstructive pulmonary disease; and any other chronic disease. In the case of other mental health illness, the question was "Has a doctor or mental health professional (psychiatrist or psychologist) ever diagnosed you with another mental illness?" In the case of a spinal column problem, the question was "Do you 
have any chronic column or neck problem, low back pain, sciatica, vertebra or disc problem?" Multimorbidity was assessed by the cutoff point of two or more morbidities. ${ }^{21-23}$ Among women, high blood pressure episodes and diabetes only during pregnancy were not considered morbidities.

The independent variables used in this study were: sex (male/female); age in full years (dichotomized as: $18-59$ years and 60 years or more), and schooling in years (categorized as: no instruction, incomplete primary education, complete elementary and incomplete high school, and complete high school until higher education). For adjustment purposes, the following variables related to health aspects were included: possession of health insurance (no/yes), coverage by the Family Health Strategy (FHS; no/yes), continuity of care explanation (no/yes), and hospitalization in the last year (no/ yes). The main independent variable used to stratify the sample of individuals with multimorbidity was the BMI, calculated using the weight ( $\mathrm{kg}$ ) and height squared (in meters), which were both measured at the time of the interview. BMI was categorized according to the cutoff points of the World Health Organization: ${ }^{24}$ low weight and eutrophy, $\leq 24.9 \mathrm{~kg} / \mathrm{m}^{2}$; overweight, $25.0-29.9 \mathrm{~kg} / \mathrm{m}^{2}$; and obesity, $\geq 30.0 \mathrm{~kg} / \mathrm{m}^{2}$.

The database was obtained from the IBGE website (http://www. ibge.gov.br/home). Statistical analyses were carried out using Stata version 15.0 (StataCorp., College Station, TX, USA), considering the sample design of the study (using the svy command). Descriptive analysis was performed, obtaining variable prevalence. All analyses were stratified for BMI. Poisson regression was used for the crude and adjusted analyses between multimorbidity and independent variables, ${ }^{25}$ estimating the prevalence ratios (PR) and their respective $95 \% \mathrm{CI}$, in addition to $P$-values for heterogeneity and linear trend (schooling). The analyses were performed using a hierarchical model; the variables included in the first level were sex, age, and schooling, and those included in the second level were the variables of health services: possession of health insurance, FHS coverage, continuity of care, and hospitalization in the last year. Variables with $P$-values that were lower than 0.20 were retained in the model, controlling for possible confounders at the same level and the level above. Associations with $P$-values $<0.05$ were considered statistically significant. Furthermore, the margins and marginsplot commands were used to present differences in the prevalence of multimorbidity according to BMI, stratified for sex and age.

To ensure the stratification of the analyses for the BMI variable, an interaction test was performed for the association between the outcome (multimorbidity) and the independent variables, testing the interaction for the third variable (BMI). For this test, in addition to the $P$-value $\leq 0.10$, the effect measures were considered.

The project was submitted to the National Research Ethics Commission and approved under protocol number 10853812.7.0000. 0008. All participants signed free and informed consent that ensured data confidentiality.

\section{RESULTS}

The total sample consisted of 59,402 individuals for whom information on diseases and BMI was available; of these, 14,291 individuals had multimorbidity. Overall, the prevalence of multimorbidity ( $\geq 2$ diseases) was $25 \%$ ( $95 \%$ CI, $24.4 \%-25.6 \%$ ). The prevalence of multimorbidity according to BMI varied, being $20.2 \%$ (95\% CI, 19.4\%-21.0\%) for those individuals with low weight/eutrophy, 25.8\% (95\% CI, 24.8\%-26.7\%) for those with overweight, and $32.5 \%$ (95\% CI, 31.2\%-33.8\%) for those with obesity. Regarding the characteristics of the total sample, the majority (52.9\%) were female, $18.0 \%$ were 60 years or older, and about $45.5 \%$ had the highest level of education (complete high school to higher education). Similar proportions were also observed when the sample was stratified according to BMI among those individuals who had multimorbidity (Table 1).

Among the individuals classified as overweight and obese, the prevalence of diseases varied, with hypertension being the most frequent, reaching $33.9 \%$ among obese individuals (Fig. 1). The prevalence of each disease, according to BMI classification, is shown in Supplementary Table 1. Fig. 2 presents the prevalence of multimorbidity according to BMI, adjusted for sex and age, showing a tendency to increase in multimorbidity with increasing BMI. For women with obesity and over the age of 60 years, the prevalence of multimorbidity was around $80 \%$.

In the crude analysis between multimorbidity and the independent variables, stratified by BMI, it can be observed that all variables were statistically associated with multimorbidity. In the adjusted analysis, in all strata of BMI, it was possible to observe a 
Table 1. Description of the general sample and of individuals with multimorbidity when stratified by BMI (National Health Survey Brazil, 2013)

\begin{tabular}{|c|c|c|c|c|c|}
\hline \multirow[b]{2}{*}{ Variable } & \multicolumn{4}{|c|}{ Multimorbidity } & \multirow[b]{2}{*}{$P^{*}$} \\
\hline & $\begin{array}{c}\text { General sample } \\
(n=59,402)\end{array}$ & $\begin{array}{l}\text { Low weight/eutrophy } \\
\qquad(n=4,390)\end{array}$ & $\begin{array}{l}\text { Overweight } \\
(n=5,437)\end{array}$ & $\begin{array}{c}\text { Obesity } \\
(n=4,410)\end{array}$ & \\
\hline Sex & & & & & $<0.001$ \\
\hline Male & $25,920(47.1)$ & $1,578(45.6)$ & $1,850(45.6)$ & $1,179(45.1)$ & \\
\hline Female & $34,282(52.9)$ & $2,812(54.4)$ & $3,587(54.4)$ & $3,231(54.9)$ & \\
\hline Age (full years) & & & & & $<0.001$ \\
\hline $18-59$ & $49,025(82.0)$ & $2,583(80.9)$ & $3,231(80.6)$ & $2,828(79.6)$ & \\
\hline$\geq 60$ & $11,177(18.0)$ & $1,807(19.1)$ & 2,206 (19.4) & $1,582(20.4)$ & \\
\hline Schooling (in years) & & & & & $<0.001$ \\
\hline No instruction & $9,434(13.7)$ & $1,066(16.8)$ & $1,183(14.3)$ & $868(15.1)$ & \\
\hline Incomplete primary school & $14,649(25.3)$ & $1,305(27.7)$ & $1,664(28.6)$ & 1,499 (30.7) & \\
\hline Complete elementary school and incomplete high school & $9,215(15.5)$ & $484(13.6)$ & $692(15.5)$ & $586(15.5)$ & \\
\hline Complete high school to higher education & $26,904(45.5)$ & $1,535(41.9)$ & $1,898(41.6)$ & $1,457(38.7)$ & \\
\hline Multimorbidity ( $\geq 2$ diseases) & & & & & $<0.001$ \\
\hline No & $45,911(75.0)$ & $21,056(79.8)$ & $16,158(74.2)$ & $7,951(67.5)$ & \\
\hline Yes & $14,291(25.0)$ & 4,390 (20.2) & 5,437 (25.8) & $4,410(32.5)$ & \\
\hline
\end{tabular}

Values are presented as number (\%). Low weight/eutrophy, BMl $\leq 24.9 \mathrm{~kg} / \mathrm{m}^{2} ;$ Overweight, BMI $25.0-29.9 \mathrm{~kg} / \mathrm{m}^{2} ;$ Obesity, BMl $\geq 30.0 \mathrm{~kg} / \mathrm{m}^{2}$.

${ }^{*}$ Chi-square test for heterogeneity between independent variables and BMl in individuals who had multimorbidity.

$\mathrm{BMI}$, body mass index; \%, prevalence according to the sampling design (swy).

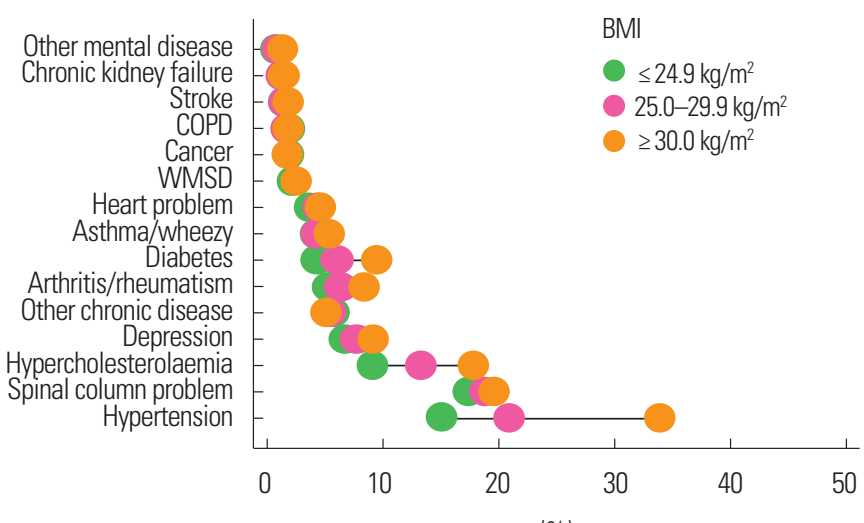

$(\%)$

Figure 1. Prevalence of chronic diseases stratified by body mass index (BMI). National Health Survey, $2013(n=59,402)$. COPD, chronic obstructive pulmonary disease; WMSD, work-related musculoskeletal disorders.

higher prevalence of multimorbidity among women and those aged 60 years or older and a lower prevalence in individuals with higher educational levels (Table 2).

\section{DISCUSSION}

Multimorbidity reached a quarter of the population and was higher among overweight and obese individuals. Considering the PNS sample, it is estimated that approximately 36,000 individuals

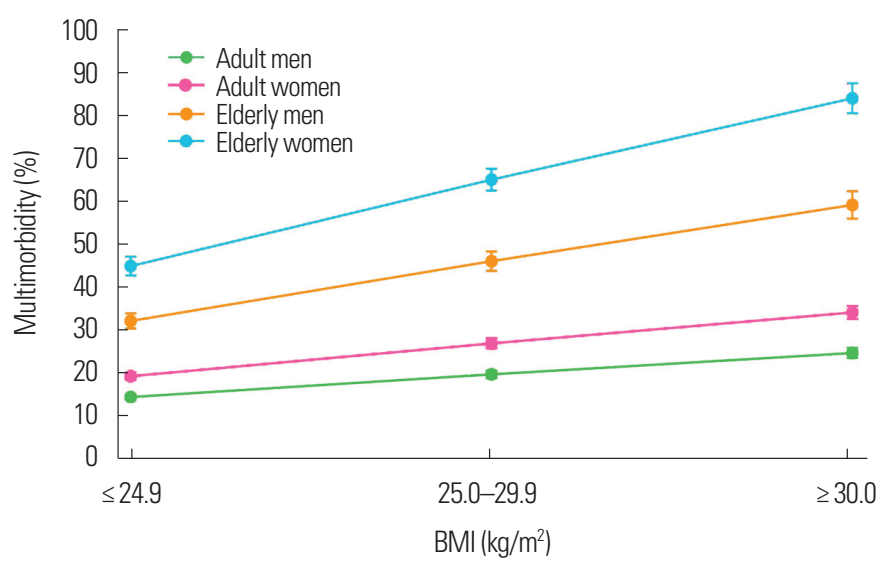

Figure 2. Prevalence of multimorbidity according to body mass index (BMI), adjusted for sex and age (adults, 18-59 years; elderly, $\geq 60$ years). National Health Survey, $2013(n=59,402)$.

overall had multimorbidity, 14,293 with overweight and 11,368 with obesity. In the analyses stratified by BMI, multimorbidity was higher among women, individuals over the age of 60 years, and individuals with a lower educational level.

The positive associations between multimorbidity and overweight/obesity, as well as the directions evidenced, are in accordance with the hypotheses that were investigated by this study, which were also observed in the relevant literature. ${ }^{26-28}$ Another study conducted with PNS data found that different groups of 
Table 2. Prevalence of multimorbidity according to independent variables and crude and adjusted analyses stratified by BMI (National Health Survey Brazil, 2013)

\begin{tabular}{|c|c|c|c|c|c|c|}
\hline \multirow{3}{*}{ Variable } & \multicolumn{6}{|c|}{ Multimorbidity (\%) } \\
\hline & \multicolumn{2}{|c|}{ Low weight/eutrophy $(n=4,387)$} & \multicolumn{2}{|c|}{ Overweight $(n=5,437)$} & \multicolumn{2}{|c|}{ Obesity $(n=4,410)$} \\
\hline & PR crude $(95 \% \mathrm{CI})$ & PRadj (95\% Cl) & PR crude (95\% Cl) & PRadj (95\% CI) & PR crude $(95 \% \mathrm{Cl})$ & PRadj (95\% CI) \\
\hline Sex & $P<0.001^{*}$ & $P<0.001^{*}$ & $P<0.001^{*}$ & $P<0.001^{*}$ & $P<0.001^{*}$ & $P<0.001^{*}$ \\
\hline Male & 1.00 & 1.00 & 1.00 & 1.00 & 1.00 & 1.00 \\
\hline Female & $1.54(1.42-1.67)$ & $1.48(1.36-1.61)$ & $1.58(1.47-1.69)$ & $1.49(1.39-1.60)$ & $1.40(1.28-1.52)$ & $1.32(1.21-1.43)$ \\
\hline Age (full years) & $P<0.001^{*}$ & $P<0.001^{*}$ & $P<0.001^{*}$ & $P<0.001^{*}$ & $P<0.001^{*}$ & $P<0.001^{*}$ \\
\hline $18-59$ & 1.00 & 1.00 & 1.00 & 1.00 & 1.00 & 1.00 \\
\hline$\geq 60$ & $3.04(2.79-3.31)$ & $2.45(2.22-2.71)$ & $2.86(2.68-3.05)$ & $2.36(2.19-2.55)$ & $2.36(2.19-2.54)$ & $2.04(1.88-2.21)$ \\
\hline Schooling (in years) & $P<0.001^{\dagger}$ & $P<0.001^{\dagger}$ & $P<0.001^{\dagger}$ & $P<0.001^{\dagger}$ & $P<0.001^{\dagger}$ & $P<0.001^{\dagger}$ \\
\hline No instruction & 1.00 & 1.00 & 1.00 & 1.00 & 1.00 & 1.00 \\
\hline Incomplete primary school & $0.92(0.82-1.03)$ & $1.07(0.96-1.19)$ & $0.87(0.78-0.95)$ & $1.00(0.91-1.09)$ & $1.09(0.98-1.22)$ & $1.18(1.06-1.31)$ \\
\hline Complete elementary school and incomplete high school & $0.51(0.44-0.60)$ & $0.73(0.62-0.85)$ & $0.56(0.49-0.64)$ & $0.75(0.66-0.86)$ & $0.68(0.58-0.80)$ & $0.89(0.76-1.04)$ \\
\hline Complete high school to higher education & $0.52(0.46-0.59)$ & $0.66(0.58-0.75)$ & $0.50(0.45-0.55)$ & $0.62(0.56-0.70)$ & $0.59(0.53-0.66)$ & $0.75(0.67-0.85)$ \\
\hline
\end{tabular}

Low weight/eutrophy, BMl $\leq 24.9 \mathrm{~kg} / \mathrm{m}^{2} ;$ Overweight, BMl $25.0-29.9 \mathrm{~kg} / \mathrm{m}^{2} ;$ Obesity, BMl $\geq 30.0 \mathrm{~kg} / \mathrm{m}^{2}$.

*Wald test for heterogeneity; ${ }^{*}$ Wald test for linear trend.

$\mathrm{BMI}$, body mass index; PR, prevalence ratio; $\mathrm{Cl}$, confidence interval; PRadj, prevalence ratio adjusted for sex, age, and schooling, plus health insurance, coverage by Family Health Strategy, continuity of care, and hospitalization in the last year.

chronic diseases were associated with high $\mathrm{BMI}{ }^{29}$ In addition to BMI, other ways to classify obesity have been studied in association with multimorbidity; for example, an assessment of body fat percentage (\% bodyfat) showed that adult populations with high percentages of body fat carry a higher risk of multimorbidity than those with higher BMI. ${ }^{28}$

In this study, when the chronic diseases that made up the multimorbidity construct were evaluated, hypertension presented the most greatest percentage difference. Some studies have identified hypertension as the most prevalent of the morbidities evaluated among individuals with higher $\mathrm{BMI} .{ }^{26,27,30}$ In addition, these results emphasize the findings of Guimarães et al., ${ }^{31}$ which indicate that weight control has a positive relationship with more suitable blood pressure measurements.

Considering sex and age, the findings showed that women with overweight and obesity, over the age of 60 years, presented a higher prevalence of multimorbidity (reaching $80 \%$ ), which is in contrast with the results found by Zhang et al., ${ }^{30}$ that the higher multimorbidity prevalence was observed among Chinese men over the age of 60 years. Nevertheless, there is a consensus on the positive association between multimorbidity and female sex, since it is measured by medical diagnosis in most surveys. ${ }^{32}$ In this context, the variables used for the adjustments were selected for their well-established relationships with both multimorbidity and BMI. ${ }^{32}$
This study points out the importance of monitoring as well as managing chronic diseases, with emphasis on obesity in women over the age of 60 years. While there is evidence demonstrating that the occurrence of chronic diseases increases with age, these conditions should not be attributed only to aging, due to the important component related to the presence of obesity. ${ }^{4,11,14} \mathrm{~A}$ study conducted in Finland found a 1.6- to 1.8-fold increase in the risk among individuals with obesity, both men and women, of having a stroke and hospitalization for any cardiovascular disease. ${ }^{33,34}$ Furthermore, obese individuals have an increased risk (1.5- to 2.2-fold) of developing diabetes according to data from a study conducted with 16 prospective cohorts from the United States and Europe, showing that the risk of cardiometabolic multimorbidity increases with BMI. ${ }^{27}$

As has been demonstrated in the general population, this study showed an association between multimorbidity and educational level, with a lower prevalence observed in more educated individuals across all BMI strata. Studies carried out in low- to moderate-income countries have consistently demonstrated the association between a lower educational level and the increased occurrence of multimorbidity. ${ }^{16,35}$ According to an analysis using PNS data, individuals with 1 to 8 years of schooling were more likely to have multimorbidity, with an OR of 1.40 (95\% CI, 1.32-1.49) for $\geq 2$ diseases and an OR of 1.58 (95\% CI, 1.45-1.72) for $\geq 3$ morbidities, 
compared to subjects with $\geq 12$ years of schooling. ${ }^{12}$

There are practical implications related to the findings of this study. A higher prevalence of diseases such as diabetes, arthritis and rheumatism, depression, high cholesterol, column problems, and hypertension was observed among obese individuals. In addition, a higher prevalence of multimorbidity was also identified among obese women over the age of 60 years. These findings draw attention to measures aimed at addressing morbidities and obesity as different conditions, but which have a strong relationship. In a temporal sequence, overweight and obesity should be considered as conditions that contribute to the emergence or aggravation of chronic diseases, for example. ${ }^{14,27}$

Some limitations of this study should be mentioned. First, there is the possibility of underestimating the multimorbidity estimate because, with the exception of depression, all other diseases were self-reported from a previous medical diagnosis. Although there are studies that validated the information reported by the interviewee considering the medical diagnosis, such as in reporting hypertension, ${ }^{36}$ it is known that self-reported information may contain some bias. However, as this study was interested in evaluating the association between multimorbidity and overweight, it is believed that this underestimation may have been diluted.

In this study, it was observed that one in four individuals presented with multimorbidity, and this proportion was significantly higher among overweight and obese individuals. The occurrence of multimorbidity increased with a higher BMI. We highlight the high prevalence of multimorbidity in obese women over the age of 60 years, as well as the high occurrence of hypertension among obese individuals. The individual's educational level was an independent factor of BMI, with a lower prevalence of multimorbidity among individuals with higher schooling.

\section{CONFLICTS OF INTEREST}

The authors declare no conflict of interest.

\section{AUTHOR CONTRIBUTIONS}

Study concept and design: TRF; acquisition of data: TRF and $\mathrm{BPN}$; analysis and interpretation of data: TRF, APSR, and BPN; drafting of the manuscript: TRF, APSR, and BPN; critical revision of the manuscript: all authors; statistical analysis: TRF and BPN; administrative, technical, or material support: BPN and DCM.

\section{SUPPLEMENTARY MATERIALS}

Supplementary Table 1 can be found via https://doi.org/10. 7570/jomes20110.

\section{REFERENCES}

1. Ng M, Fleming T, Robinson M, Thomson B, Graetz N, Margono C, et al. Global, regional, and national prevalence of overweight and obesity in children and adults during 19802013: a systematic analysis for the Global Burden of Disease Study 2013. Lancet 2014;384:766-81.

2. Global Burden of Metabolic Risk Factors for Chronic Diseases Collaboration (BMI Mediated Effects), Lu Y, Hajifathalian K, Ezzati M, Woodward M, Rimm EB, et al. Metabolic mediators of the effects of body-mass index, overweight, and obesity on coronary heart disease and stroke: a pooled analysis of 97 prospective cohorts with 1.8 million participants. Lancet 2014;383:970-83.

3. Blüher M. Obesity: global epidemiology and pathogenesis. Nat Rev Endocrinol 2019;15:288-98.

4. Silveira EA, Vieira LL, Souza JD. High prevalence of abdominal obesity among the elderly and its association with diabetes, hypertension and respiratory diseases. Cien Saude Colet 2018;23:903-12.

5. Marengoni A, Angleman S, Melis R, Mangialasche F, Karp A, Garmen A, et al. Aging with multimorbidity: a systematic review of the literature. Ageing Res Rev 2011;10:430-9.

6. Salisbury C, Johnson L, Purdy S, Valderas JM, Montgomery AA. Epidemiology and impact of multimorbidity in primary care: a retrospective cohort study. Br J Gen Pract 2011;61: e12-21.

7. Taylor AW, Price K, Gill TK, Adams R, Pilkington R, Carrangis $\mathrm{N}$, et al. Multimorbidity: not just an older person's issue. Results from an Australian biomedical study. Soc Psychiatry Psychiatr Epidemiol 2011;46:351. 
8. World Health Organization. World report on ageing and health. Geneva: World Health Organization; 2015.

9. Bloom DE, Chatterji S, Kowal P, Lloyd-Sherlock P, McKee M, Rechel B, et al. Macroeconomic implications of population ageing and selected policy responses. Lancet 2015;385:649-57.

10. Boyd CM, Fortin M. Future of multimorbidity research: how should understanding of multimorbidity inform health system design? Public Health Rev 2010;32:451-74.

11. Canizares M, Hogg-Johnson S, Gignac MA, Glazier RH, Badley EM. Increasing trajectories of multimorbidity over time: birth cohort differences and the role of changes in obesity and income. J Gerontol B Psychol Sci Soc Sci 2018;73:1303-14.

12. Nunes BP, Chiavegatto Filho AD, Pati S, Cruz Teixeira DS, Flores TR, Camargo-Figuera FA, et al. Contextual and individual inequalities of multimorbidity in Brazilian adults: a crosssectional national-based study. BMJ Open 2017;7:e015885.

13. Agborsangaya CB, Ngwakongnwi E, Lahtinen M, Cooke T, Johnson JA. Multimorbidity prevalence in the general population: the role of obesity in chronic disease clustering. BMC Public Health 2013;13:1161.

14. Booth HP, Prevost AT, Gulliford MC. Impact of body mass index on prevalence of multimorbidity in primary care: cohort study. Fam Pract 2014;31:38-43.

15. Lebenbaum M, Zaric GS, Thind A, Sarma S. Trends in obesity and multimorbidity in Canada. Prev Med 2018;116:173-9.

16. Afshar S, Roderick PJ, Kowal P, Dimitrov BD, Hill AG. Multimorbidity and the inequalities of global ageing: a cross-sectional study of 28 countries using the World Health Surveys. BMC Public Health 2015; 15:776.

17. Costa CD, Flores TR, Wendt A, Neves RG, Tomasi E, Cesar JA, et al. Inequalities in multimorbidity among elderly: a population-based study in a city in Southern Brazil. Cad Saude Publica 2018;34:e00040718.

18. Pathirana TI, Jackson CA. Socioeconomic status and multimorbidity: a systematic review and meta-analysis. Aust N Z J Public Health 2018;42:186-94.

19. Szwarcwald CL, Malta DC, Pereira CA, Vieira ML, Conde WL, Souza Júnior PR, et al. National Health Survey in Brazil: design and methodology of application. Cien Saude Colet 2014;19:333-42.
20. Souza-Júnior PRB de, Freitas MPS de, Antonaci G de A, Szwarcwald CL. Sample design of the National Health Survey 2013. Epidemiol e Serviços Saúde 2015;24:207-16.

21. Fortin M, Stewart M, Poitras ME, Almirall J, Maddocks H. A systematic review of prevalence studies on multimorbidity: toward a more uniform methodology. Ann Fam Med 2012; 10:142-51.

22. Harrison C, Britt H, Miller G, Henderson J. Examining different measures of multimorbidity, using a large prospective crosssectional study in Australian general practice. BMJ Open 2014; 4:e004694.

23. Johnston MC, Crilly M, Black C, Prescott GJ, Mercer SW. Defining and measuring multimorbidity: a systematic review of systematic reviews. Eur J Public Health 2019;29:182-9.

24. World Health Organization. Fact sheet: obesity and overweight [Internet]. Geneva: World Health Organization; 2020 [cited 2021 May 1]. Available from: https://www.who.int/ news-room/fact-sheets/detail/obesity-and-overweight

25. Barros AJ, Hirakata VN. Alternatives for logistic regression in cross-sectional studies: an empirical comparison of models that directly estimate the prevalence ratio. BMC Med Res Methodol 2003;3:21.

26. Price AJ, Crampin AC, Amberbir A, Kayuni-Chihana N, Musicha C, Tafatatha T, et al. Prevalence of obesity, hypertension, and diabetes, and cascade of care in sub-Saharan Africa: a cross-sectional, population-based study in rural and urban Malawi. Lancet Diabetes Endocrinol 2018;6:208-22.

27. Kivimäki M, Kuosma E, Ferrie JE, Luukkonen R, Nyberg ST, Alfredsson L, et al. Overweight, obesity, and risk of cardiometabolic multimorbidity: pooled analysis of individual-level data for 120813 adults from 16 cohort studies from the USA and Europe. Lancet Public Health 2017;2:e277-85.

28. Jawed M, Inam S, Shah N, Shafique K. Association of obesity measures and multimorbidity in Pakistan: findings from the IMPACT study. Public Health 2020;180:51-6.

29. de Carvalho JN, de Camargo Cancela M, de Souza DL. Lifestyle factors and high body mass index are associated with different multimorbidity clusters in the Brazilian population. PLoS One 2018; 13:e0207649.

30. Zhang L, Ma L, Sun F, Tang Z, Chan P. A multicenter study 
of multimorbidity in older adult inpatients in China. J Nutr Health Aging 2020;24:269-76.

31. Guimarães JM, Griep RH, Fonseca MJ, Duncan BB, Schmidt MI, Mill JG, et al. Four-year adiposity change and remission of hypertension: an observational evaluation from the Longitudinal Study of Adult Health (ELSA-Brasil). J Hum Hypertens 2020;34:68-75.

32. Nguyen H, Manolova G, Daskalopoulou C, Vitoratou S, Prince M, Prina AM. Prevalence of multimorbidity in community settings: a systematic review and meta-analysis of observational studies. J Comorb 2019;9:2235042X19870934.

33. Hu G, Tuomilehto J, Silventoinen K, Sarti C, Männistö S, Jousilahti P. Body mass index, waist circumference, and waisthip ratio on the risk of total and type-specific stroke. Arch In- tern Med 2007;167:1420-7.

34. Joshy G, Korda RJ, Attia J, Liu B, Bauman AE, Banks E. Body mass index and incident hospitalisation for cardiovascular disease in 158546 participants from the 45 and Up Study. Int J Obes (Lond) 2014;38:848-56.

35. Arokiasamy P, Uttamacharya U, Jain K, Biritwum RB, Yawson $\mathrm{AE}, \mathrm{Wu}$ F, et al. The impact of multimorbidity on adult physical and mental health in low- and middle-income countries: what does the study on global ageing and adult health (SAGE) reveal? BMC Med 2015;13:178.

36. Chrestani MA, Santos Ida S, Matijasevich AM. Self-reported hypertension: validation in a representative cross-sectional survey. Cad Saude Publica 2009;25:2395-406. 